\title{
Health status of slaughtered animals as indicated by postmortem inspection at slaughterhouses
}

\author{
Simona Ninčáková ${ }^{1}$, Vladimír Večerek ${ }^{2}$, Lenka Válkováa ${ }^{2}$ Eva Voslářová2, \\ Michal Kaluža ${ }^{2}$, Veronika Zavřelová ${ }^{2}$ \\ ${ }^{1}$ Central Veterinary Administration of the State Veterinary Administration, \\ Department of Animal Health and Welfare, Prague, Czech Republic \\ ${ }^{2}$ University of Veterinary Sciences Brno, Faculty of Veterinary Hygiene and Ecology, \\ Department of Animal Protection and Welfare and Veterinary Public Health, Brno, Czech Republic
}

Received August 26, 2021

Accepted September 30, 2021

\begin{abstract}
The study focused on the comparison of health of cattle, pigs, sheep, goats, rabbits, poultry and ostriches slaughtered in slaughterhouses in the Czech Republic based on the occurrence of findings detected during a postmortem veterinary inspection in the period from 2010 to 2019 . The level of health was expressed as the so-called PA index obtained by the ratio of the number of findings to the total number of observations (15) during the pathoanatomical examination in the slaughterhouse multiplied by one hundred. Mammals (cattle, pigs, sheep and goats) generally had a higher PA index than birds (domestic chickens, turkeys, ducks, geese, ostriches), with the exception of kids and rabbits. The highest PA index was found in cows (15.13) and piglets (12.18); whereas the lowest PA index was found in broiler chickens (0.102), rabbits, and geese (both 0.14). In poultry, the PA index values were below 1, with the exception of laying hens (PA index 2.165). A higher PA index was found in a group of adult animals (the PA index ranged from 2.17 to 15.13) and groups of young animals culled from farms (the PA index ranged from 10.79 to 12.18 ) than in fattened animals (the PA index ranged from 0.10 to 5.32). A comprehensive overview of the health condition of slaughtered animals enables the farmers, veterinarians, transporters and slaughterhouse operators to take appropriate and precisely targeted preventive measures, thereby increasing the animal welfare and health in the future while reducing the incidence of carcass damage.
\end{abstract}

Cattle, sheep, goats, pigs, poultry, rabbits

Veterinary inspection of animals and their carcasses in slaughterhouses is the most widespread and also the longest-used tool of veterinary supervision. The primary purpose of this inspection is to identify animals whose meat and organs are unfit for human consumption and to remove them from the food chain. However, veterinary inspection is also of great importance in terms of epizootiology and animal health control. The potential of veterinary inspection, which has not yet been fully appreciated and sufficiently used, lies in the possibility of identifying and reflecting current issues of livestock welfare (Stark et al. 2014, Stark 2017). The pathoanatomical changes that can be identified from the carcasses of slaughtered animals can be monitored much more easily and accurately during postmortem inspection in slaughterhouses (Huneau-Salaun et al. 2015). A thorough analysis of the frequency of trends in the occurrence of pathoanatomical findings can provide the farmers and veterinarians with a feedback, on the basis of which they can apply appropriate preventive measures and thus eliminate the risk of endangering animal health as well as prevent economic losses on farms (Ceccarelli et al. 2018; Januskeviciene et al. 2010). Although inspection reports (especially the postmortem ones) provide a large amount of information on the health and condition of food animals, this potential has not yet been systematically exploited in most countries (Stark 2017).

Address for correspondence:

Prof. Ing. Eva Voslarova, Ph.D.

Department of Animal Protection and Welfare and Veterinary Public Health

Faculty of Veterinary Hygiene and Ecology

University of Veterinary Sciences Brno

Palackeho tr. 1946/1, Brno 612 42, Czech Republic 
Most of the existing studies that deal with causes of the condemnation of carcasses or the pathoanatomical findings identified during postmortem veterinary inspection at a slaughterhouse in general focus on a specific species of livestock, such as cattle (Tabaran et al. 2018; Kaluža et al. 2020, 2021), pigs (Hansson et al. 2000; Kongsted and Sorensen 2017; Večerek et al. 2020a,b), rabbits (Drozd et al. 2019; Válková et al. 2021), broiler chickens (Jakob et al. 1998; Ferreira et al. 2012; Amini et al. 2015; Buzdugan et al. 2020), laying hens (Keutgen et al. 1999), turkeys (Lupo et al. 2010) or ostriches (Dzoma et al. 2009). Due to the differences in the focus of the studies, the methodology for evaluating the findings, the duration and extent of the monitoring (often data from only one or a few slaughterhouses), the inter-species comparison of the frequency of PA findings is difficult. Studies that monitor, analyse and compare pathoanatomical findings in several species or categories of livestock under the same conditions and during the same period are rare. Januskeviciene et al. (2010) analysed and compared the incidence of pathological lesions in livestock (cattle, pigs, sheep, goats, horses), rabbits, game and poultry (broiler chickens, turkeys, ducks) in Lithuania; their survey was carried out in 2007-2009. Ceccarelli et al. (2018) analysed the reasons for the condemnation of carcasses and organs of cattle, pigs, sheep and horses in selected slaughterhouses in central Italy in the period of 2010-2016. Lis (2005) monitored the incidence of pathological findings in cattle, pigs, sheep and horses in slaughterhouses in Poland in 2003. Salines et al. (2017) compared the causes of condemnation of carcasses in broilers, turkeys, ducks and guinea fowl slaughtered in France over a one-year period (2012 to 2013). The frequency of pathoanatomical findings in laying hens, broiler chickens and turkeys detected during postmortem veterinary inspection was compared by Večerek et al. (2019) and Večerková et al. (2019).

The aim of this study was to evaluate the health condition of cattle, pigs, sheep, goats, rabbits, poultry (laying hens, broiler chickens, turkeys, ducks, geese) and ostriches raised in farms in the Czech Republic and slaughtered in slaughterhouses in the Czech Republic in the period from 2010 to 2019 based on the results of postmortem inspection.

\section{Materials and Methods}

The level of animal health was assessed on the basis of the frequency of pathoanatomical findings determined during veterinary inspections in slaughterhouses in animals slaughtered in the Czech Republic in the period from 2010 to 2019. The level of health was expressed as the so-called PA index obtained by the ratio of the number of findings to the total number (15) of evaluations during the pathoanatomical examination in the slaughterhouse multiplied by one hundred. The PA index thus expressed a value enabling comparison of the health condition of the individual species and categories of slaughtered animals in a specified period of time.

The health of cattle was assessed in the categories of cows, heifers, bulls for fattening, calves; the health of pigs in the categories of sows, pigs for fattening, piglets; the health of sheep in the category of ewes and lambs; the health of goats in the category of does and kids, the health of rabbits; the health of poultry in the categories of laying hens, broiler chickens, turkeys, ducks and geese; and the health of ostriches.

For each animal, 15 evaluations were performed focusing on the organ or tissue units or the body parts as follows: liver, kidneys, lungs, gastrointestinal tract, spleen, heart, nervous system, skin, genitals and mammary glands, head, torso, limbs, muscle, other findings and the whole organism (including findings of underdevelopment [stunting], emaciation, ascites, abscesses, tuberculoid changes, cysticercosis). For each evaluation, a conclusion was made with or without a finding. For each species and category of slaughtered animals, a total number of findings and the number of evaluations were obtained for the entire monitored period of 10 years. The ratio of the number of findings to the number of evaluations multiplied by one hundred represented the value expressing the level of health using the PA index of findings taking numerical values from 0 to 100 .

The overall level of health for each species and category of slaughtered animals was assessed on the basis of the PA index values. By comparing the PA indices among the individual species and categories of slaughtered animals, differences between them were determined.

Furthermore, the level of health was compared within the individual categories of the species and also between the species within a group of adult animals, animals for fattening or growing and within a group of young animals culled from farms.

The data were statistically evaluated using the Unistat v. 6.5 for Excel program (Unistat Ltd., London, UK). Chi-square test was used to evaluate the statistical significance within the $2 \times 2$ contingency table procedure. At frequencies exceeding 5, Yates correction was used, at frequencies below 5, Fisher's exact test was used. 


\section{Results}

Comparison of the values of the PA index among individual species and categories of animals slaughtered in slaughterhouses in the Czech Republic in the period from 2010 to 2019 is given in Table 1 and Fig. 1. The values of the PA index expressing the ratio of the number of findings to the number of evaluations during veterinary inspection in the slaughterhouse in the monitored species and categories of animals ranged from 0.102 (broiler chickens) to 15.129 (cows). This range demonstrates significant differences in the level of health among the species and categories of slaughtered animals.

A PA index higher than 10.00 was found in cows, piglets and calves and it documents a significantly $(P<0.05)$ lower level of health of these species and categories compared to other species and categories of slaughtered animals. A PA index ranging from 9.99 to 1.01 was found in sows, sheep, heifers, finisher pigs, bulls, goats, lambs and laying hens. A PA index of less than 1.00 was found in turkeys, kids, ducks, ostriches, rabbits, geese and broiler chickens. The lowest PA index was found in broiler chickens, its value was significantly lower than in all other species and categories of animals.

The inter-species comparison shows that the highest PA index and thus the worst level of health of slaughtered animals was found in cattle (cows 15.129; calves 10.785; heifers 5.323; bulls 3.196) and pigs (piglets 12.176; sows 7.723; fattening pigs 5.279).

Comparison of the PA index in a group of adult animals, a group of fattening or growing animals, and a group of young animals culled from farms shows that a higher PA index was found in the group of adult animals (2.165-15.129) and the group of animals culled from farms (10.785-12.176) compared to fattened animals (0.102-5.323).

Table 1. The PA index (the ratio of the number of findings to the total number of evaluations during the pathoanatomical examination in the slaughterhouse multiplied by one hundred) for species and categories of animals slaughtered within the period from 2010 to 2019.

\begin{tabular}{|c|c|c|c|c|c|}
\hline $\begin{array}{l}\text { Animal } \\
\text { species }\end{array}$ & $\begin{array}{l}\text { Animal } \\
\text { category }\end{array}$ & $\begin{array}{c}\text { Number of } \\
\text { animals slaughtered }\end{array}$ & $\begin{array}{c}\text { Number of } \\
\text { pathoanatomical findings }\end{array}$ & $\begin{array}{c}\text { Number of } \\
\text { postmortem evaluations }\end{array}$ & PA index \\
\hline \multirow{4}{*}{ Cattle } & Cows & 1136754 & 2579609 & 17051310 & $15.129^{\mathrm{a}}$ \\
\hline & Heifers & 257912 & 205946 & 3868680 & $5.323^{\mathrm{f}}$ \\
\hline & Bulls & 1015541 & 486901 & 15233115 & $3.196^{\mathrm{h}}$ \\
\hline & Calves & 104459 & 168983 & 1566885 & $10.785^{\circ}$ \\
\hline \multirow{3}{*}{ Pigs } & Sows & 586245 & 679175 & 8793675 & $7.723^{d}$ \\
\hline & Finisher pigs & 25027303 & 19817045 & 375409545 & $5.279^{\mathrm{g}}$ \\
\hline & Piglets & 123191 & 225002 & 1847865 & $12.176^{\mathrm{b}}$ \\
\hline \multirow{2}{*}{ Sheep } & Ewes & 22815 & 19358 & 342225 & $5.657^{\mathrm{e}}$ \\
\hline & Lambs & 114264 & 39999 & 1713960 & $2.334^{\mathrm{i}, \mathrm{j}}$ \\
\hline \multirow{2}{*}{ Goats } & Does & 1348 & 483 & 20220 & $2.389^{\mathrm{i}, \mathrm{j}}$ \\
\hline & Kids & 5778 & 627 & 86670 & $0.723^{1, \mathrm{~m}}$ \\
\hline Rabbits & Rabbits & 1876929 & 40206 & 28153935 & $0.143^{\mathrm{p}, \mathrm{q}}$ \\
\hline \multirow{2}{*}{$\begin{array}{l}\text { Domestic } \\
\text { chickens }\end{array}$} & $\begin{array}{l}\text { Broiler } \\
\text { chickens }\end{array}$ & 1089406687 & 16678958 & 16341100305 & $0.102^{\mathrm{r}}$ \\
\hline & End-of-lay hens & 20030744 & 6503610 & 300461160 & $2.165^{\mathrm{k}}$ \\
\hline Turkeys & Turkeys & 1181598 & 132261 & 17723970 & $0.746^{\mathrm{l}, \mathrm{m}}$ \\
\hline Geese & Geese & 37690 & 799 & 565350 & $0.141^{\mathrm{p}, \mathrm{q}}$ \\
\hline Ducks & Ducks & 28579765 & 1052604 & 428696475 & $0.246^{\mathrm{n}, \mathrm{o}}$ \\
\hline Ostriches & Ostriches & 6252 & 229 & 93780 & $0.244^{\mathrm{n}, \mathrm{o}}$ \\
\hline
\end{tabular}

a-r different superscripts for the PA indices express a significant difference between the individual species and categories of animals $(P<0.05)$ 


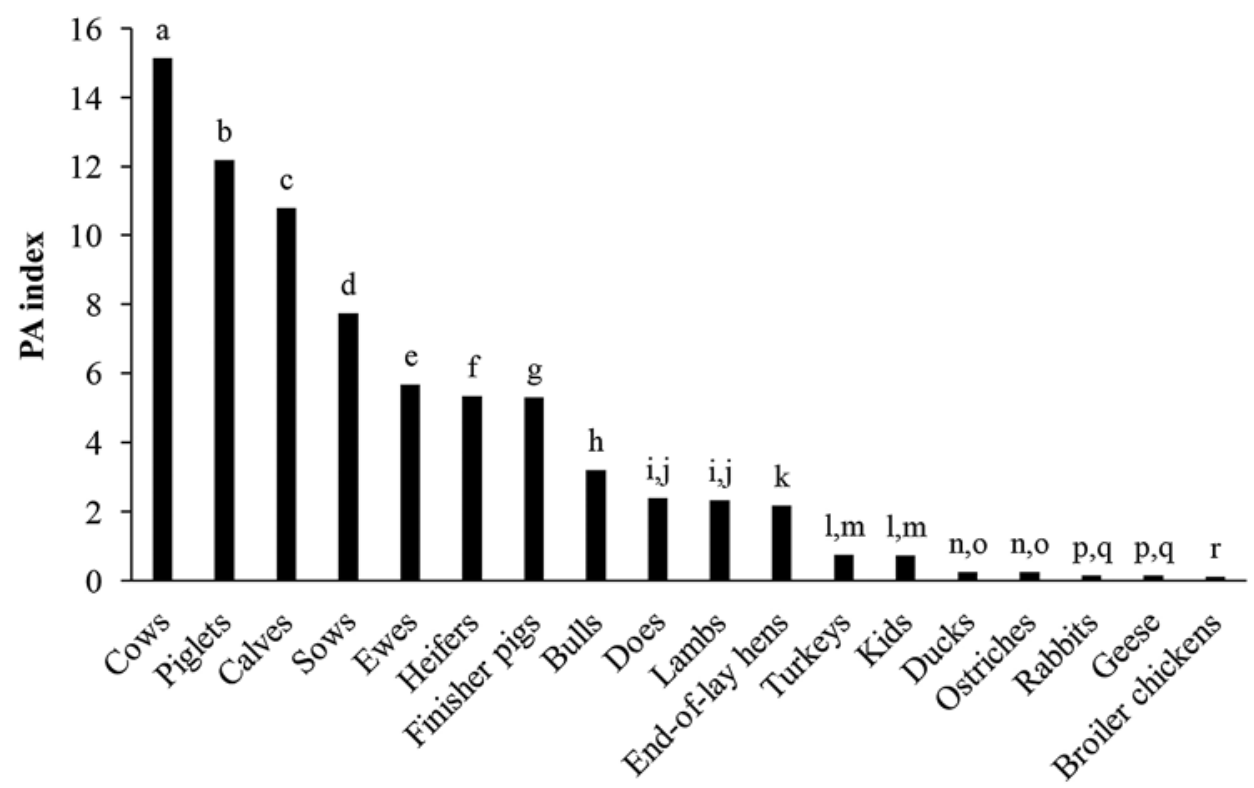

Animal species/category

Fig. 1. Comparison of the PA index (the ratio of the number of findings to the total number of evaluations during the pathoanatomical examination in the slaughterhouse multiplied by one hundred) of individual species and categories of animals slaughtered in the slaughterhouse.

${ }^{a-r}$ different letters for the PA indices express a significant difference between the individual species and categories of animals $(P<0.05)$

\section{Discussion}

The results of the study document significant differences in the number of findings made during the veterinary inspection in the slaughterhouse, and thus in the level of health of different species and categories of animals at the time of slaughter. Mammals (cattle, pigs, sheep and goats) generally had a higher PA index than birds (domestic chickens, turkeys, ducks, geese, ostriches), with the exception of kids and rabbits. This is probably due to the shorter length of production life of slaughtered birds, but the method of rearing or genetic equipment (resistance, temperament) of the individual animal species can also have a certain effect. Januskeviciene et al. (2010) reached similar conclusions, determining most pathoanatomical findings in pigs $(14.92 \%)$ and cattle $(9.08 \%)$, and fewest in poultry $(0.90 \%)$ and rabbits $(0.13 \%)$.

Our results show that the most affected category was that of cows (PA index 15.129). Both dairy cows and cows without market milk production stay on farms significantly longer compared to other livestock. The high intensity of production in dairy cows together with the longer period of use on farms have an impact on the level of health and also on the possible occurrence of production diseases, which are associated with characteristic findings at slaughterhouses. In cows without marketable milk production, the presence of health problems is mainly due to their long life on farms. The effect of age on the rate of confiscation in slaughterhouses was also reported by Dupuy et al. (2013). Deteriorated health levels in terms of the frequency of pathological findings were also found in calves 
(PA index 10.785). In contrast, a good level of health in cattle was observed in bulls (PA index 3.196) and heifers (PA index 5.323). Bulls and heifers are kept mainly extensively and usually slaughtered within 24 months, which decreases the risk of disease and thus of findings detected during the veterinary inspection. Similarly, Nichols on et al. (2013) in the USA or Dupuy et al. (2013) in France found a lower rate of findings in bulls compared to cows. The differences between the categories may also be related to the different treatment of bulls and cows in slaughterhouses (Večerek et al. 2021).

Besides cattle, the worst level of health was detected in pigs. A high rate of confiscation in pigs was also reported by Ceccarelli et al. (2018) or Lis (2005). The results of our study showed that, in contrast to cattle, the most frequently detected findings in pigs are within the youngest category, i.e. in piglets (PA index 12.176). The health condition of sows (PA index 7.723) was better compared to slaughtered piglets. In both cases, these are animals culled from farms due to impaired health or production. The lower incidence of pathological findings in finisher pigs demonstrates the good level of health achieved in this category even in the conditions of conventional fattening, to which the elimination of piglets with inadequate condition and health at the beginning of fattening also contributes (Lopez-Verge et al. 2018).

In general, better levels of health compared to cattle and pigs were observed in sheep and goats. Torina et al. (2004) point out that up to $80 \%$ of pathologies in sheep and goats is associated with the presence of parasites. A higher incidence of findings in sheep than in goats found in our study may result from different farming methods in the Czech Republic and their behaviour on pasture, affecting the risk of parasitic infection. While sheep are reared all year round or for most of the year on pastures, goats usually have access to pasture only during the season and only for a certain part of the day, or they are reared in stables year-round. Furthermore, unlike sheep that prefer to graze closer to the ground, for goats, it is natural to selectively graze on the leaves of shrubs and trees and to avoid areas with faeces (Yiakoulaki and Papanastasis 2009; Fox et al. 2013).

Rabbits had the lowest PA index among mammals. In the slaughterhouse, mainly meat rabbits are usually slaughtered, which means that they are young animals in good condition (Schwartzkopf-Genswein et al. 2012). High mortality of rabbits during transport to the slaughterhouse may also play a role (Voslářová et al. 2018). It is possible that rabbits that are not in an optimal health condition die during transport and therefore are not slaughtered. Rampin et al. (2008) reported pathological findings in 1\% of rabbit carcasses in a slaughterhouse in Italy, mainly lesions in the digestive and urinary tract.

In poultry, the PA index values were below 1, with the exception of laying hens (PA index 2.165). The time spent on the farm, the housing system and the use of laying hens differ significantly from other slaughtered poultry. While broiler chickens, geese, ducks and turkeys are slaughtered after weeks up to months of fattening and are therefore usually young birds in a good condition, laying hens are sent for slaughter after about a year of intensive egg production. In addition, in the Czech Republic laying hens are still predominately housed in cages in contrast to other poultry, which is usually kept on litter in growout houses. Salines et al. (2017) found significantly fewer pathoanatomical findings in free-range poultry. The effect of age, housing system and time spent on farms is especially obvious in the difference between the rate of the PA findings in laying hens (2.165) and broiler chickens (0.102), i.e. the same animal species (domestic chicken). In broiler chickens, the lowest PA index of all monitored species and categories of animals was found; at the same time, it is also a category slaughtered at the youngest age. Only a slightly higher PA index was found in geese (0.141). The likely explanation is that it is a relatively undemanding and adaptable species, which is also often farmed extensively (pasture with grazing, access to water) taking into account the natural needs of this species (Tremolada et al. 2020). On the contrary, most PA findings among fattened poultry were 
found in turkeys. Correspondingly, Januskeviciene et al. (2010) determined more PA findings in turkeys compared to broilers and ducks. A closer analysis of the findings in turkeys in their study revealed that most of the lesions were located on the limbs $(85.79 \%)$. Also Sanotra et al. (2001) and Krautwald-Jungehanns (2003) confirm that pathological processes on the limbs are a frequent finding in intensively reared turkeys (especially males). Their high weight causes the turkey tarsometatarsi to be in intense contact with the litter and thus to be more prone to skin lesions (Salines et al. 2017).

Commercial ostrich farms and the transport of ostriches to slaughterhouses are still relatively rare in the Czech Republic. All ostrich-keeping systems are based on their natural living conditions and they are kept exclusively in combination with a free-range outdoor enclosure. Increased attention is paid to the care and handling of ostriches, with regard to both the potential danger of these animals and the prevention of degrading their skin which is also of economic value (Meyer et al. 2003; Engelbrecht et al. 2009). Nevertheless, PA findings were recorded even in ostriches at not an entirely negligible level (PA index 0.244 ). From this point of view and due to the absence of relevant studies, it is desirable to direct further research to a more detailed analysis of the nature and causes of the findings in ostriches.

In all monitored animal species, a lower PA index was recorded in the category of fattened animals compared to the category of young animals culled from farms (calves, piglets) or end-of-production animals (cows, sows, laying hens). Especially in older and culled animals, the likelihood of impaired welfare during transport and slaughter and subsequently also the quality of carcasses is high, as their economic value is low and they often do not receive adequate care (Grandin 2001). Fattened animals are sent to the slaughterhouse because they have reached the optimal slaughter indicators (age, weight) and not because they have been culled from the farm due to a worse condition, as is the case of young or post-productive animals. Due to their good condition and robust body structure (Schwartzkopf-Genswein et al. 2012), fattened animals are also more resistant to adverse factors (capture, loading into transport containers or vehicles, unfamiliar environment, mixing of unknown individuals, handling, unfavourable climatic conditions, the duration of transport, etc.) that might endanger their health condition during transport and handling in the slaughterhouse (Grandin 2001; Eicher et al. 2006; Fike and Spire 2006).

Data on the occurrence of pathoanatomical findings obtained from slaughtered animals during postmortem veterinary examination are very valuable both from the point of view of scientific research and, above all, from the point of view of the prevention of negative effects on the health of livestock. A comprehensive overview of the health condition of slaughtered animals enables the farmers, veterinarians, transporters and slaughterhouse operators to take appropriate and precisely targeted preventive measures, thereby increasing the animal welfare and health in the future while reducing the incidence of carcass damage.

\section{Acknowledgements}

This study was supported by ITA VETUNI (Project No. 2021ITA22).

\section{References}

Amini K, Zachar T, Popowich S, Knezacek T, Goodhope B, Willson P, Gomis S 2015: Association of increased rate of condemnation of broiler carcasses due to hepatic abnormalities with immunosuppressive diseases in the broiler chicken industry in Saskatchewan. Can J Vet Res 79: 261-267

Buzdugan SN, Chang YM, Huntington B, Rushton J, Guitian J, Alarcon P, Blake DP 2020: Identification of production chain risk factors for slaughterhouse condemnation of broiler chickens. Prev Vet Med 181: 105036

Ceccarelli M, Leprini E, Sechi P, Iulietto MF, Grispoldi L, Goretti E, Cenci-Goga BT 2018: Analysis of the causes of the seizure and destruction of carcasses and organs in a slaughterhouse in central Italy in the 2010-2016 period. Ital J Food Saf 7: 6899 
Drozd L, Paszkiewictz W, Pyz-Lukasik R 2019: Post-slaughter changes in rabbit carcasses in Poland between 2010 and 2018. Med Weter 75: 613-616

Dupuy C, Morignat E, Maugey X, Vinard JL, Hendrikx P, Ducrot C, Calavas D, Gay E 2013: Defining syndromes using cattle meat inspection data for syndromic surveillance purposes: a statistical approach with the 2005-2010 data from ten French slaughterhouses. BMC Vet Res 9: 1-17

Dzoma BM, Pansiri E, Segwagwe BVE 2009: A retrospective study on the prevalence of ostrich carcass and organ condemnations in Botswana. Trop Anim Health Pro 41: 443-448

Eicher SD, Cheng HW, Sorrels AD, Schutz MM 2006: Behavioral and physiological indicators of sensitivity or chronic pain following tail docking. J Dairy Sci 89: 3047-3051

Engelbrecht A, Hoffman LC, Cloete SWP, van Schalkwyk SJ 2009: Ostrich leather quality: a review. Anim Prod Sci 49: $549-557$

Ferreira TZ, Sesterhenn R, Kindlein L 2012: Economic losses of main causes of condemnation of the broiler carcass in a slaughterhouse under Federal Inspection on Rio Grande do Sul, Brazil. Acta Sci Vet 40: 1021

Fike K, Spire MF 2006: Transportation of cattle. Vet Clin North Am Food Anim Pract 22: 305-320

Fox NJ, Marion G, Davidson RS, White PCL, Hutchings MR 2013: Modelling parasite transmission in a grazing system: The importance of host behaviour and immunity. PLoS ONE 8: 1-11

Grandin T 2001: Perspectives on transportation issues: The importance of having physically fit cattle and pigs. J Anim Sci 79: E201-E207

Hansson I, Hamilton C, Ekman T, Forslund K 2000: Carcass quality in certified organic production compared with conventional livestock production. J Vet Med B Infect Dis Vet Public Health 47: 111-120

Huneau-Salaun A, Stark KDC, Mateus A, Lupo C, Lindberg A, Le Bouquin-Leneveu S 2015: Contribution of meat inspection to the surveillance of poultry health and welfare in the European Union. Epidemiol Infect 143: $2459-2472$

Jakob HP, Morgenstern R, Albicker P, Hoop RK 1998: Condemnation reasons of slaughtered broilers from two major Swiss producing companies. Schweiz Arch Tierh 140: 60-64

Januskeviciene G, Paulauskas V, Dailidaviciene J, Juozaitiene V 2010: Analysis of pathologic lesions in the livestock and poultry slaughtered in the meat establishments of Lithuania. Vet Zootec 52: 33-42

Kaluža M, Večerek V, Voslářová E, Semerád Z, Passantino A 2020: Assessing the standard of health and welfare in individual categories of cattle from the viewpoint of intravital pathological changes. Agriculture-Basel 10: 619

Kaluža M, Večerek V, Voslářová E, Semerád Z, Passantino A 2021: Incidence of characteristic findings during veterinary carcass inspections 2010-2019 in the Czech Republic and the relation to the level of health and welfare of individual classes of cattle. Animals 11: 537

Keutgen H, Wurm S, Ueberschar S 1999: Pathologic changes in end-of-lay hens with regards to different housing systems. Deut Tierarztl Woch 106: 127-133

Kongsted H, Sorensen JT 2017: Lesions found at routine meat inspection on finishing pigs are associated with production system. Vet J 223: 21-26

Krautwald-Jungehanns ME 2003: Putenproduktion in Deutschland: Ansätze für eine tierschutzgerechte Haltung. Deutsche Tierärzteblatt 1: 4-8

Lis H 2005: Results of veterinary inspection of slaughter animals and meat in Poland in 2003. Med Weter 61: $1160-1161$

Lopez-Verge S, Gasa J, Farre M, Coma J, Bonet J, Sola-Oriol D 2018: Potential risk factors related to pig body weight variability from birth to slaughter in commercial conditions. Transl Anim Sci 2: 383-395

Lupo C, Le Bouquin S, Allain V, Balaine L, Michel V, Petetin I, Colin P, Chauvin C 2010: Risk and indicators of condemnation of male turkey broilers in western France, February-July 2006. Prev Vet Med 94: 240-250

Meyer A, Cloete SWP, Brown CR, van Schalkwyk SJ 2003: The persistence to slaughter age of scars resulting from damage inflicted to ostrich skins during the grow-out phase. S Afr J Anim Sci 33: 32-37

Nicholson JDW, Nicholson KL, Frenzel LL, Maddock RJ, Delmore RJ, Lawrence TE, Henning WR, Pringle TD, Johnson DD, Paschal JC, Gill RJ, Cleere JJ, Carpenter BB, Machen RV, Banta JP, Hale DS, Griffin DB, Savell JW 2013: Survey of transportation procedures, management practices, and health assessment related to quality, quantity, and value for market beef and dairy cows and bulls. J Anim Sci 91: 5026-5036

Rampin F, Piccirillo A, Schiavon E, Poppi L, Grilli G 2008: Detection of pathological lesions in slaughtered rabbits. Ital J Anim Sci 7: 105-111

Salines M, Allain V, Roul H, Magras, C, Le Bouquin S 2017: Rates of and reasons for condemnation of poultry carcases: harmonised methodology at the slaughterhouse. Vet Rec 180: 516-516

Sanotra GS, Lawson LG, Vestergaard KS 2001: Influence of stocking density on tonic immobility, lameness, and tibial dyschondroplasia in broilers. J Appl Anim Welf Sci 4: 71-87

Schwartzkopf-Genswein KS, Faucitano L, Dadgar S, Shand P, Gonzalez LA, Crowe TG 2012: Road transport of cattle, swine and poultry in North America and its impact on animal welfare,carcass and meat quality: A review. Meat Sci 92: 227-243

Stark KDC 2017: Abattoir condemnation data remain underused in decision making. Vet Rec 180: 514-515

Stark KDC, Alonso S, Dadios N, Dupuy C, Ellerbroek L, Georgiev M, Hardstaff J, Huneau-Salaun A, Laugier C, Mateus A, Nigsch A, Afonso A, Lindberg A 2014: Strengths and weaknesses of meat inspection as a contribution to animal health and welfare surveillance. Food Control 39: 154-162 
Tabaran A, Dan SD, Reget O, Tabaran AF, Mihaiu M 2018: Slaughterhouse survey on the frequency of pathologies found in bovine post-mortem inspections. Bull UASVM Vet Med 75: 251-255

Tremolada C, Bielińska H, Minero M, Ferrante V, Canali E, Barbieri S 2020: Animal-based measures for the on-farm welfare assessment of geese. Animals 10: 890

Torina A, Dara S, Marino AMF, Sparagano OAE, Vitale F, Reale S, Caracappa, S 2004: Study of gastrointestinal nematodes in Sicilian sheep and goats. Ann N Y Acad Sci 1026: 187-194

Válková L, Večerek V, Voslářová E, Zavřelová V, Conte F, Semerád Z 2021: The health and welfare of rabbits as indicated by post-mortem findings at the slaughterhouse. Animals 11: 659

Večerek V, Večerková L, Voslářová E 2019: Comparison of the frequency of patho-anatomic findings in laying hens with findings in broiler chickens and turkeys detected during post-mortem veterinary inspection. Poultry Sci 98: 5385-5391

Večerek V, Voslářová E, Semerád Z 2020a: Patho-anatomic findings in finisher pigs, sows and piglets detected during veterinary slaughterhouse inspection. Acta Vet Brno 89: 341-347

Večerek V, Voslářová E, Semerád Z, Passantino A 2020b: The health and welfare of pigs from the perspective of post mortem findings in slaughterhouses. Animals 10: 825

Večerek V, Voslářová E, Kameník J, Machovcová Z, Válková L, Volfová M, Konvalinová J 2021: The effect of slaughtering skills on the welfare of cattle during stunning with a captive bolt. Acta Vet Brno 90: 109-116

Večerková L, Voslářová E, Večerek V 2019: Comparison of the welfare of laying hens, broiler chickens and turkeys in terms of bird health as surveyed during inspection in slaughterhouses. Acta Vet Brno 88: 243-248

Voslářová E, Večerek V, Bedáňová I, Večerková L 2018: Mortality in rabbits transported for slaughter. Anim Sci J 89: 931-936

Yiakoulaki M, Papanastasis V 2009: Foraging behaviour of sheep and goats grazing on silvopastoral systems in Northern Greece. Options Méditerr 85: 79-84 